Trent M Kays:

\title{
Digital Education and Oppression: Rethinking the Ethical Paradigm of the Digital Future
}

\begin{abstract}
:
Digital education seems to often be approached from the perspective of educational structures that existed before contemporary technology. In this way, the old structures of oppression are replicated in the spaces most capable of liberation. This article offers a conversation about a future digital education that not only enacts the goals of liberation but also works to embed social justice concepts into the oppressive structures that liberation seeks to topple. Enacting a new ethical paradigm is needed to address the issues of the digital age and education, and this article attempts to build such a paradigm that can be applied to contemporary and future iterations of educational ventures.
\end{abstract}

\section{Agenda:}

Introduction 65

Some Thoughts on the Ethics of Digital Education 65

Theorizing a Digital (Education) Future 67

A New Paradigm 69

Conclusion. 70

Author(s):

Trent M Kays:

- Graduate Instructor, Department of Writing Studies, University of Minnesota, Minneapolis, Minnesota, USA

- $₫$ kays@umn.edu, $\square$ www.trentmkays.com

- Relevant Publications:

- Blog and Wiki Discourse, International Encyclopedia of Language and Social Interaction (2014), In press-Forthcoming. Co-author(s): Laura Gurak.

- Technical Communication Education in a Digital, Visual World, IEEE International Professional Communication Proceedings (2012): 274-279. Co-author(s): Dawn Armfield, Laura Gurak, and Joe Weinberg 


\section{Introduction}

In Teaching to Transgress, bell hooks argues, "The classroom remains the most radical space of possibility in the academy" (1994: 12). When hooks argued this point, the pervasiveness of online and digital education did not exist. The rise in such education demands a reinterpretation of the academy's dedication to the radicalness of the classroom space.

The notion of social justice as a topic that can be interrogated within classroom spaces calls for a new paradigm in the digital age. The act of confession-one inherent in social justice-influence classrooms-shows that social justice and liberatory pedagogy are concepts easily and rightly seized upon by students, despite that students often employ the tenets of such concepts without realizing the power structures that dominate their own classroom spaces (Orner, 1992: 84).

The confessional act fundamentally changes when confronted with the speed and reach of the digital age. Therefore, such an act becomes influenced by the disturbed power structures in which it is employed. These power structures call for a new ethical paradigm. Coupled with this new ethical paradigm, the radicalness of the classroom space-and by extension the academy-seeks an uncertain end. Such an ethical paradigm is troubled by the unchartered territory of the digital age, and, thus, said paradigm can only be fully interpreted through past ethical discussions. While Aristotle wrote about ethics over 2000 years ago, the notion of "the good is what everything seeks" is burdened by the pervasiveness and access of information through online and digital mediums (1999: 1.1-2).

Education is guided by an ethic that ultimately values the student, but this ethic is not always present in discussions of classroom spaces. If the notion of oppression is accepted, the practice of liberation must be the concern of education (Freire). These issues are solely based in situated and contextual practices (Derrida, 1997: 158-159), yet said practices can only exist in an educational framework freed of the traditional power structures that regulate the ethical choices of those within it. In short, the oppressed can only be liberated by educational power structures if said structures are hitherto liberated from oppression.

This seemingly contradictory notion of education and oppression is the basis of contemporary and future digital education. Such education provides an opening in which new dialogue about the oppressed and the oppressor can be inserted and through which a new ethical paradigm can be established. The future of digital education is a future dominated by a discussion where the why of education gives way to the how of education. Meaning, more access does not necessarily mean less oppression.

A digital education that reflects and respects the notions of social justice and liberatory pedagogy can only be understood through an ethical paradigm that accounts for the technological abundance of the $21^{\text {st }}$ century. The future of digital education is bound to the populations it serves. While education certainly can serve populations in need, education done digitally must account not only for the populations served but also the technology used to distribute the oppressive power structures inherent in traditional education.

\section{Some Thoughts on the Ethics of Digital Education}

The history of digital education is the history of technology. Indeed, the tension arising out of online and technologically-mediated education is one concerned not so much with the distant past but, instead, the distant future. The distinction between perception and happening shrinks because, in many ways, education is a lifelong experience punctuated by moments of technological advancement. Such interruptions create "disjunctions" around the very technologies that humanity relies on:

Tensions about technology surround us. A leading source of our current anxieties about technology is the troubling gap that often exists between what we think and what we see, or, in slightly more precise terms, the disjunction between our normative expectations for technology and what we observe and 
experience in the world around us. We perceive technology to be changing quickly, I believe, because we are continually confronted with the social and cultural and economic changes in which technology is clearly involved. (Misa, 2004: 273)

What is to be made of such disjunctions? They are the contested spaces in which technology and education intersect and, often, violently clash. Technology progresses quickly; however, education does not progress so quickly. The ethical subject-one surrounded by the established ethical paradigms of others-is bound to be destroyed by the fraught nature of forcing together technology and education. They are, of course, in a way indissoluble, but they are also complicated by their distinct purposes in $21^{\text {st }}$ century human survival.

The speed and reach that technology affords complicates the function of education. Speed and reach, time and space seem tenuous terms to describe the complications of the $21^{\text {st }}$ century Internet; however, the problems that plagued early iterations of the Internet continue presently. The digitization of worldly affairs means "everything is in the here and now. Before very long, the whole world will be on disk. Salvation is but a modem away" (Bouman, 1996: 1). Salvation is a morally burdened term for what the Internet has fashioned. One could argue Western education heretofore has been a practice of monoculturalism. The classroom as educational space is such that the priority of the dominant culture-most often a Western cultural perspective-is valued above and, occasionally, in place of the inherent multiculturalism of students and teachers. The totality of education was one where a single thought, a single way, and a single understanding was forced onto students (hooks, 1994: 35). Alas, digital education may not-though it is possible-offer salvation from the dominant monocultural narrative of Western thought.

If anything is to be gained by a world saturated by digital education, it is access to more profound multiculturalism; however, this does not guarantee that the multiculturalism encountered will be valued. Even more problematic is that there is no promised space in which multiculturalism and education coexist and coincide with the digital. Indeed, digital education-and the communities from which it draws-offers more an opportunity to locate like-minded individuals rather than culturally and socially distinct counterparts. As Stephen DohenyFarina suggests, "[V]irtual communities offer us an opportunity to construct utopian collectivities-communities of interest, education, tastes, beliefs, and skills. In cyberspace we can remake the world out of an unsettled landscape" (1998: 16). This, then, cannot be a goal of digital education, especially if such education is understood as an ethical enterprise. Ethics in education is a place of defining, and one cannot define ethics in an echo chamber.

Still, this presents an opportunity for understanding the potential of digital education as an ethical project. Is digital education something that seeks good and, thus-according to Aristotle-something that is ethical? Education is not neutral, and it is inherently a political changeling altering its size and goal constantly. Yet, when education and ethics is discussed, often the discussion is based on academic integrity, but this is not the ethics with which digital education should be concerned. Instead, the concern should be put toward the notion of whether education should be digital at all and the meaning of such education.

If digital education reproduces the same oppressive structures from past incarnations of education, then it has already failed. Digital education should be an education that has liberation as its main objective. This, of course, has not always been the case in any vestige of education; however, it must be the main objective of digital education because of the potential for vast liberation. Ethically, the notion of pushing students toward liberation must account for their probable acculturation into a liberatory ethos. If a student is forced into liberation, the very guide said student relies on has become his or her oppressor and the importance of the student-teacher interaction is destroyed.

Take for example massive open online courses (MOOCs). While online education is not necessarily new, MOOCs $^{147}$ are a bastardized, if not well-intended, attempt at spreading education. Far from revolutionary, MOOCs offer a special type of profit-driven promise. They are a "business venture seeking to promise educational efficiency-more students served-at lower per students costs" (Carbone, 2014: 193). MOOCs in many

147 The MOOCs in question are those known as XMOOCs or broadcast MOOCs, often operated by Udacity, Coursera, etc. 
ways are the warning digital education must consider before progressing into the realm of a complete and transformative pedagogical practice. The only thing MOOCs offer that traditional online education does not is massivity; however, where traditional online education can attempt to value the student-teacher interactionan interaction vital to the process and goal of social justice and liberatory pedagogy-MOOCs can only postulate on the illusion of newness; MOOCs are, in essence, a temporal phenomena, a "restatement of online learning environments" that existed before such online massivity (Glance, Forsey, and Riley, 2013).

Moreover, the plethora of student information now held within spaces of digital education should be enough to give pause to any discussion of such education. Certainly, the location of and access to student information has always been an ethical question. In the United States, this question posed such a problem that a law was specifically written to address it: the Family Educational Rights and Privacy Act (FERPA), which "protects the privacy of student education records" (United States Department of Education, 1974).

What role education plays in the $21^{\text {st }}$ century is a question of ethics. If digital education can offer salvation to the masses of oppressed, it can also offer unfortunate and expedient methods through which oppressors can continue to exist and enact an ideology bent on a subjugated future. The purpose of educators in the present and future of the digital, then, is to combat the forces of those willing to use education as a tool against liberation and for the captivity of the digitally educated mind. Thusly, digital education cannot be a reproduction of the educational practices of the last century nor can they be completely informed by contemporary educational practices. Instead, digital education must be a practice informed by spaces and futures meant to achieve-though perhaps never attaining - a utopian vision of a humanistic future.

\section{Theorizing a Digital (Education) Future}

If digital education cannot simply be a reproduction of past educational practice, then what can it be? Of course, this becomes a definitional issue. "Digital education" as terminology is itself not new, and it does provide a warning on impressing such terminology for acts far from the digital:

The concept of digital education is being a little too freely applied. Like the child with a hammer, who sees everything as a nail, everything that can even remotely be seen as digital education is being described as such. Without two-way communication and feedback, much of what passes for digital education today more closely resembles reading a book (sometimes a really thin book) rather than taking a course. (Peck, 2000: 52)

Certainly, not every incarnation of education can be digital; however, in the Western world, this may be the case; or, perhaps, every style of Western education has digital components. Briefly and for the purposes of theorizing a future consumed by digital education, three characteristics should be assumed:

1. A digital education is an educational venture connected in some way to the digital tools (computers, mobile phones, tablets, etc.) present within the cultural and societal structures through which it arose.

2. A digital education is an educational venture connected in some way to the tools and technologies (browsing, word processing, etc.) of the Internet and with the means to use said tools and technologies of the Internet.

3. Finally, a digital education is an educational venture averse to and not oriented toward the spatial aspects (buildings, physical classrooms, etc.) of past and, in many ways, contemporary learning.

Since it is the nature of education in the $21^{\text {st }}$ century, these characteristics exist in a state of flux. As mentioned previously, the history of digital education is the history of technology; therefore, as with technology, digital education is-and must be-in a constant state of change, spurning the static nature of past educational ventures and structures. Formal education, as it currently exists, will not end with the simple application of the digital (Male and Burden, 2013: 1-3). It would be foolish to think so because no matter how digital something becomes there is always a need for a guide in some time and some place. 
A "digital future" may be too conceited terminology. It assumes that the digital future has not yet arrived, or that such a future will somehow be different from what presently exists. For the most part, technology exists to affect change via a digital education; however, the politics of education-in all forms-seems to prohibit or cloud the pace at which such change could be achieved. For example: It is not difficult for a teacher to assign work that engages cultural and societal differences outside the classroom and through social media.

The problems that often are proffered with social media use runs a gamut from cyberbullying to distraction to in-class disobedience. These are problems that are reported in nightly newscasts and that draw the concern of such newscasts' audiences. In addition, digital education can be subjected to behavior prevalent in most online communication, like flaming, trolling, and other uninhibited behavior. In her 2001 book, Cyberliteracy: Navigating the Internet with Awareness, Laura Gurak describes such behavior as "techno-rage" and the "online manifestation of road rage" (47-53). As digital education will most likely use some form of online communication, such behavior becomes critical to digital awareness. Therein rests at least one ethical issue of digital education.

In embracing the digital future, a focus on navigating the treacherous and vitriolic nature of some online communication must be paramount. Moreover, ethically, is it appropriate to subject those most in need of liberation to the oppressive nature of such language? To knowingly place students, teachers, and others in a space where they could be verbally and mentally abused while attempting to fulfill their own liberatory acts is a dangerous precedent; however, this does not mean such issues will disappear, as they are part of the oppressive structure in which liberation is desperately needed.

Instead, it may become unethical to not subject students to such behavior. Meaning, it is unethical to ill-prepare students for an often violent world that awaits them. Thus, navigating such spaces becomes increasingly relevant to digital education and the future it provides. As such, the digital future and education should expressly be the domain of a social justice and liberatory ethos and pedagogy. Most pedagogies are not equipped to deal with the inherent and institutional variables often reproduced in digital and online spaces.

If the connection of digital education and the potential of a digital future are currently representative of the oppressive structures confining students, teachers, and others to their circumstances, a pedagogy based in acts of liberation and social conscience will provide the tools for the oppressed to free themselves from whatever and whomever is their oppressor. Ironically, an educational giant from the $20^{\text {th }}$ century can best speak to systemic oppression: Paulo Freire.

Freire's pivotal work-Pedagogy of the Oppressed-directly challenges what it means to educate and how to fight oppression. Freire never had to contend with the challenges of the digital age. Digital education, the Internet, and $21^{\text {st }}$ century technology escaped his critical interrogation; however, Freire's work is equally applicable. For Freire-and the educational activists and thinkers who followed his lineage-liberation is the answer to oppression. Such work must be the goal of the oppressed: "to liberate themselves and their oppressors as well" (2010: 44). For digital education, this Freirean imperative becomes crucial for, as suggested earlier, the great utopian vision. The oppressed are capable of liberating themselves with the correct tools and tactics; the most valuable method of liberation is through engaged dialogue among and through those involved (2010: 65). Indeed, this type of method is one based in a combination of theory and praxis, developing from "the breaks, discontinuities, and tensions in history, all of which become valuable in that they highlight the centrality of human agency and struggle while simultaneously revealing the gap between society as it presently is and society as it might be" (Giroux, 2009: 47). The gap, as described by Henry Giroux, is the place of disjunctions (Misa, 2004: 273). This gap is where the difficult work of theory, praxis, and ethics combine to address the digital education of the present and future. The gap that is formed and in which this difficult work exists embodies the "lived practice" necessary for remolding existing paradigms (Freire, 2001: 40).

The affects of the digital age allow students, teachers, and others to experience lived practice in ways not afforded past educational incarnations. The almost constant connection to the Internet in the Western world provides an opportunity to experience varying cultures and societies once inaccessible to many, especially those from poor and lower class backgrounds. Freirean notions of liberation and social justice become increasingly vital to digital education and the oppressive structures inherent in contemporary society. Social justice provides 
a basis to affect change in that it often encourages a reevaluation of the structures that exist (Coates, 2007: 585), whereas liberatory pedagogy alone assumes a somewhat static structure. These approaches are best suited to each other because they both have action as their focus. Within digital education, the ability to liberate oneself should be paramount. The breadth and access of the Internet and other digital devices provide the opportunity to more fully and completely end the domination of the oppressor (Freire, 2010: 183), while reorienting marginalized groups (i.e. often the oppressed) into the center of the ongoing dialogue (Coates, 2007: 586-587).

\section{A New Paradigm}

The digital age is dynamic and unflinching in its evolution, moving ever forward and leaving those behind who are unwilling to change. Knowing this, any digital and ethical paradigm offered must embrace the eventuality of both insignificant and significant change. This change is not limited to technology; it must also include the students, teachers, and others who most benefit from the omnipresent connection that is available to a large portion of the world. Critically, this paradigm must account for the application of pedagogy to technology. Too often, the pedagogy employed by teachers can become stale and worn. Meaning, teachers are loath to change and understand their pedagogical practice as in a constant state of renewal.

Pedagogy is both formalized and rebellious. Given the appropriate circumstances, pedagogical practice is such that it needs "to be worked out again and again" (Ellsworth, 2011: 305). Of course, relying on the process of technology does not guarantee the liberatory and social justice project that digital education should embody. It would be foolish to consider such a process as one where the natural output is critical engagement or consciousness (Freire, 2005: 30-31); therefore, a new paradigm must account for this issue while equally empowering students to work toward their own ends.

Through a discursive process, digital education can be continually refined; thus, the following characteristics of a new paradigm must be understood as moments in time: They will pass and new characteristics will arise to meet new challenges. As education continues to live and move in the digital age, three characteristics should guide its ethical and new paradigm:

1. Education in the digital age must employ Internet technologies to encourage the confessional acts that are vital to understanding social justice and liberatory acts.

2. Education in the digital age must address the privileged and complicated nature of technology in the classes, societies, and cultures of not only the oppressed but also the oppressor, so, then, both can be liberated from oppression.

3. Finally, education in the digital age must reimagine the classroom as a global networked environment that is connected to both privileged and impoverished populations and where the pursuit of radical embodiment and student agency is paramount to course content.

These characteristics are easily attainable in any contemporary Western classroom. Unfortunately, the application of this ethical paradigm does not guarantee liberation or the challenging of systemic issues inside and outside the classroom. Students may recognize such liberation and be unable to act; consequently, it is the responsibility-the ethical recourse-of educators to assist students through action (Gabel, 2002: 195-196). Furthermore, it is possible that such liberation, especially when confessional acts à la social justice are used, will result in dichotomized and limited traps: "narratives of victims/saviors and of villains/heroes" (Diab et al, 2013). Despite this, digital education can foster a strong sense of reflection and, in turn, avoid these potential problems. Any serious attempt at a digital education must include critical reflection on the practice of liberation (Freire, 2001: 43-45), and this type of reflection is the foundation of the aforementioned and new ethical paradigm, which seeks to address the fraught and complicated potential of the digital future. 


\section{Conclusion}

The future-digital or not-waits for no one. It waits for no student, no teacher, and no person. As the present barrels toward the future, the impact of the digital on education will become increasingly complex and dense. It will fall on educators to explore and help students understand the starkly turbulent future of education and said students' role in it. One of the fundamental roles critical teachers can play is to lead students in the direction of a more socially and ethically just world (Giroux, 2010). This must be the ultimate goal of a liberatory and social justice oriented digital education. The digital future is unknown, but students, teachers, and others can be best equipped to meet this unknown terrain with the tools provided by a critical consciousness raising and radical embodiment of education in the $21^{\text {st }}$ century.

\section{References}

Aristotle: Nicomachean Ethics. Trans. Terence Irwin. Indianapolis, United States, Hackett. 1999.

Bouman, O: Realspace in Quicktimes: Architecture and Digitization. Rotterdam, the Netherlands, NAi Publishers. 1996.

Carbone, N: Here a MOOC, There a MOOC. Invasion of the MOOCs: The Promise and Perils of Massive Open Online Courses. Eds. Steven Krause and Charles Lowe. Anderson, United States, Parlor Press. 2014: 193203.

Coates, R: Social Justice and Pedagogy. American Behavioral Scientist 51.4, (2007): 579-591.

Derrida, J: Of Grammatology. Trans. Gayatri Chakravorty Spivak. Baltimore, United States, Johns

Hopkins University Press. 1997.

Diab, R, et al: Making Commitments to Racial Justice Actionable. Across the Disciplines 10.3, (2013): np. Available at: http://wac.colostate.edu/atd/race/diabetal.cfm.

Doheny-Farina, S: The Wired Neighborhood. New Haven, United States, Yale UP. 1998.

Ellsworth, E: The Wicked Problem of Pedagogy, An Afterword. Learning Through Digital Media: periments in Technology and Pedagogy. Ed. R Trebor Scholz. New York, United States, iDC. 2011: 305311.

Freire, P: Education for Critical Consciousness. New York, United States, Continuum. 2005.

Freire, P: Pedagogy of Freedom: Ethics, Democracy, and Civic Courage. Lanham, United States, Rowman \& Littlefield. 2001.

Freire, P: Pedagogy of the Oppressed. New York, United States, Continuum. 2010.

Gabel, S: Some Conceptual Problems with Critical Pedagogy. Curriculum Inquiry 32.2, (2002): 177-201.

Giroux, H: Critical Theory and Educational Practice. The Critical Pedagogy Reader, 2nd Edition. Eds. Antonia Darder, Marta Baltodano, and Rodolfo Torres. New York, United States, Routledge. 2009: 27-51.

Giroux, H: Lessons to be Learned from Paulo Freire as Education is Being Taken Over by the Mega Rich. Truthout, (2010): np. Available at http://truth-out.org/archive/component/k2/item/93016:lessons-to-belearned-from-paulo-freire-as-education-is-being-taken-over-by-the-mega-rich.

Glance, D, M Forsey, and M Riley: The Pedagogical Foundations of Massive Open Online Courses. First Monday 18.5, (2013): np. Available at http://firstmonday.org/ojs/index.php/fm/article/view/4350/3673.

Gurak, L: Cyberliteracy: Navigating the Internet with Awareness. New Haven, United States, Yale University Press. 2001.

hooks, b: Teaching to Transgress: Education as the Practice of Freedom. New York, United States, Routledge. 1994.

Male T and K Burden: Access Denied? Twenty-First-Century Technology in Schools. Technology,

Pedagogy and Education, (2013): 1-16.

Misa, T: Leonardo to the Internet: Technology and Culture from the Renaissance to the Present.

Baltimore, United States, Johns Hopkins University Press. 2004. 
Orner, M: Interrupting the Calls for Student Voice in Liberatory Education: A Feminist Postructuralist Perspective. Feminisms and Critical Pedagogy. Eds. Carmen Luke and Jennifer Gore. New York, United States, Routledge. 1992: 74-90.

Peck, R: Web-based Digital Education Opportunities. The Journal of Academic Librarianship 26.1, (2000): 4952.

United States Department of Education: Family Educational Rights and Privacy Act (FERPA). Washington DC, United States, 20 U.S.C. \& 1232g; 34 CFR Part 99. 1974. Available at https://www.ed.gov/policy/gen/guid/fpco/ferpa/index.htm/. 